\section{AN INSIDIOUS FORM OF "COVERING."}

\section{To the Editors of THE LANCET.}

SIRs,-Much has been said and written of late respecting the abolition of the unqualified assistant and also the act of "covering" unqualified practitioners by qualified men. There is to my mind yet another phase of this question which it would be well for the General Medical Council to consider-that is, the covering of unqualified practitioners under the name of midwires by qualified men. A case has recently come under my care by being asked to call at once to a house. On my arrival I found it to be a case of labour and, to use the midwife's expression, "her patient was having a difficult time." This unqualified woman had been in attendance for three hours and had succeeded in pulling off one arm of the child, and it was only after having done this that she discovered it was not a leg and this caused her to send for me. It was with some difficulty that I was able to deliver the patient of a full term male child minus one arm and of course dead from hæmorrhage. Although I have attended this case without any hope of fee or reward I feel conscious of having violated one of the laws of the General Medical Council and rendered myself liable to be struck off the Register, for it is entirely by the aid of other qualified practitioners and myself in the neighbourhood that this unqualified woman is able to continue to carry on the practice of midwifery for gain and I have no besitation in saying that she gets a good living at it. I am not in favour of the employment of unqualified assistants, but I do think that the time has arrived when unqualified practitioners of midwifery should be abolished as well as those of medicine and surgery. Portsmouth, Feb 7th, 1898

$$
\text { I am, Sirs, yours faithfully. }
$$

RICHARD EMMETT.

\section{THE EPIDEMIC AT HATTON ASYLUM. To the Editors of THE LANOWT.}

SIRS,-In reply to your letter concerning the epidemic at Hatton Asslum I herewith submit to you the following facts :-

All the food used at the ball was cooked on the asylum premises. No tinned food of any description was used. All the meat and poultry came off the asylum farm and was all slanghtered on Jan. 18th and 19th. The rabbits, of which only thirty were used, were shot during the four days prior to the ball and were cooked by the housekeeper, remaining for twelve hours in earthenware pans and seasoned prior to being made into pies on the 20th. The following is a list of various articles of food on the supper tables: Beef, ham, tongue, rabbit-pie, pork-pie, goose, chicken, tipsy cake, jelly, blancmange, mince-pies, beer, lemonade, tea and coffee and bread. Of 61 attendants and servants who have had the disease 5 ate beef, 23 ate ham, 10 ate tongue, 10 ate rabbit-pie, 7 ate pork-pie, 21 ate goose, 23 ate chicken, 17 ate tipsy cake, 30 ate jelly, 18 ate blancmange, 12 ate mincepies, 37 drank beer, 35 drank lemonade, 26 drank tea and coffee, 39 ate bread.

Presuming that the epidemic was due to ptomaine poisoning it is evident that all the food was in a diseased state, eren to the jelly and blancmange, as some of these sixty-one attendants ate no meat whatever and three of them were not at the ball and had no food from it. The outbreak commenced on Jan. 13th and has continued up to yesterday, Feb. 7th. Fourteen cases occurred prior to the 21st, on the 22nd there were 29 cases, on the 23rd 47, on the 24th 21 , on the 25th 23 , on the 26th 12 , on the 27 th 13 , since which date there have been 26 . The medical staff of the asylum have attended 185 cases, of which 85 were lunatics, the remainder being employed in various departments, some residing at their own homes.

The disease has been remarkably sudden in its onset. Vomiting and diarrhoea have been present in nearly all cases (some, however, have had no abdominal symptoms whatever), severe rigors, pains in the back and limbs, high temperature (reaching $103^{\circ}$ and $104^{\circ} \mathrm{F}$.). Sudden crises, in many cases accompanied by profuse perspiration, have been the general characters of the disease ; among other symptoms may be mentioned coryza, pains at back of eyes, severe headache, and sleeplessness. The vomited matter has in nearly all cases contained bile and a marked icteric tinge has been noticed in many cases. The duration of the disease has been about a week, but some of the earlier cases have not yet recovered. All have complained of feeling great weakness and lassitude after the attack. For some hours after the crisis the majority of temperatures have been subnormal to the extent of $1^{\circ}$ to $2^{\circ}$. I hold abundant proof of the infective nature of the disease. I know it existed here and at a neighbouring asylum prior to the 21st ult. and I also know that influenza of a marked type was in the room on the night of the ball. I know of similar cases in other parts of the country.

The above-mentioned facts have led me to form the opinion that the disease is influenza. Gastric influenza is reported from the Continent but personally I have not seen what I have thought to be cases of this disease prior to the outbreak. In fairness to myself I should like it stated that with the exception of the editor of one local paper who applied to me for information per telephone and the editor of one medical journal who made full inquiry here concerning the outbreak, neither myself nor $\mathrm{my}$ assistants have been asked to state anything concerning the disease whatever it might be ; all the news which has been supplied to the public has been fabricated in Warwick and elsewhere. Asylums and their officials are never treated fairly by the lay press and I am never foolish enough to expect it. The present case is no exception. I have had the law (per the coroner) and the press have the profits.

I am, Sirs, yours faithfully,

Hatton Asylum, Feb. 8th, 1898.

Medical Superintendent.

** We are much obliged to Dr. Miller for this letter, which seems to us to dispose of the view that the epidemic was due to ptomaine poisoning.-ED. L.

\section{CORONERS AND MEDICAL MEN.}

\section{To the Editors of THE LANOET.}

SIRS,-That you deserve thanks for calling attention to the remarks made by the coroner over the case at Attercliffe Common everyone connected with the profession will admit. Too often this is the tone adopted by coroners towards medical men and were it only the particular medical man concerned who suffered this would be bad enough; unfortunately this is not the case, the evil is far reaching, for these remarks are made in open court, where a large proportion of the people are perhaps uneducated, and therefore such opinions have greater weight than if expressed before an andience the majority of whom are persons of education and refinement. Hearing a man express such views, can we wonder that bone-setters and herbalists are so largely resorted to by the working classes? And if such insults as that offered by the coroner in this inquiry to the medical profession be allowed to pass unnoticed, is it any wonder that the profession generally fails to occupy the status that it deserves? That it does not do so is a fact which none will, I believe, challenge.

With regard to the inquiry at Attercliffe Common itself, surely it cannot be regarded as settled-i.e., if the object of the inquiry really be to determine the cause of death-for here we have a man qualified to give a scientific opinion stating his belief to be that the canse of death was phthisis, this opinion being deliberately set aside by the coroner for that of some women absolutely uneducated and unskilled in medicine, surgery, and pathology. Surely a proper representation to the Home Secretary or the Lord Chancellor would be quite sufficient to cause the inquiry to be reopened and so a proper conclusion as to the cause of death arrived at Feb. 9th, 1898 I am, Sirs, yours faithfully,

FREDRRICK BROOKE.

\section{"THE WHOLE QUESTION OF NURSING." To the Editors of THE LANOET.}

SIRS, - In justice to the Incorporated Medical Practitioners' Association, I must ask your permission to make a short reply to the letter which appeared in your columns on Feb. 5th over the signature of $G$. B. Hudson. I learn from his letter that he is a Member of Parliament-a fact which, if I may quote his own words, "is quite unknown to the general public."

Your readers doubtless wondered what was the object of 